\title{
Magnetic nanoparticles: Properties and potential applications*
}

\author{
Laura L. Vatta ${ }^{\ddagger}$, Ron D. Sanderson, and Klaus R. Koch ${ }^{\dagger}$ \\ Department of Chemistry and Polymer Science, University of Stellenbosch, \\ Private Bag X1, Matieland 7602, South Africa
}

\begin{abstract}
Magnetic particles may be used to selectively attach and manipulate or transport targeted species to a desired location under the influence of an external magnetic field. By virtue of their size, magnetic nanoparticles are superparamagnetic, offering great potential in a variety of applications in their bare form or through coating with a surface coating and functional group chosen for a specific application. In this paper, and in order to illustrate this concept, three applications for the use of magnetic nanoparticles will be discussed, namely, in magnetic liquids for densimetric separation, in therapeutic and diagnostic testing, and in effluent processing and metal ion removal.
\end{abstract}

Keywords: magnetic nanoparticles; superparamagnetic; magnetic liquids; densimetric separation; medical applications; effluent processing; metal ion removal.

\section{INTRODUCTION}

Nanostructured materials often possess unique electrical, chemical, structural, and magnetic properties allowing for use in a variety of novel applications including information storage, biosensing applications, and biomedical engineering [1,2]. Nanoparticles possessing magnetic properties offer great advantages in that they can provide selective attachment to a functional molecule, confer magnetic properties to the target, and allow manipulation and transportation to a desired location through the control of a magnetic field produced by an electromagnet or permanent magnet [3].

Magnetic nanoparticle carriers consist of three functional parts: a magnetic core, a surface coating, and a functionalized outer coating.

At the center of the carrier is the superparamagnetic core which allows for the magnetic manipulation of the particle in the presence of an external magnetic field. The composition of the magnetic core is dependent on the application. For example, magnetite $\left(\mathrm{Fe}_{3} \mathrm{O}_{4}\right)$ and maghemite $\left(\gamma-\mathrm{Fe}_{2} \mathrm{O}_{3}\right)$ with high oxidative stability are currently the only accepted nontoxic magnetic materials for medical applications [4,5]. Magnetic cores consisting of materials such as cobalt, nickel, and neodymium-iron-boron may offer improved magnetic properties, however, these materials may be susceptible to oxidation or be toxic for use in the human body [6]. Magnetic nanoparticles may be synthesized by physical vapor deposition [1], mechanical attritioning [1,7], and via chemical routes [1,7,8].

By virtue of their size, magnetic nanoparticles are able to overcome the influence of the gravitational field, magnetic field gradient, and the potential magnetic agglomeration which could result when particles come into contact with one another [9]. On the other hand, particles may be attracted to one

\footnotetext{
*Paper based on a presentation at the $3^{\text {rd }}$ IUPAC Workshop on Advanced Materials (WAM III), Stellenbosch, South Africa, 5-9 September 2005. Other presentations are published in this issue, pp. 1619-1801.

*E-mail: laura@sun.ac.za

†Corresponding author: E-mail: krk@sun.ac.za
} 
another as a result of London-type van der Waals attractive forces. In order to minimize such interactions of the particle with the system environment, to ensure stability, and to prevent agglomeration, a surface coating may be required to provide steric repulsion [10].

The functionalized outer coating may be a component such as a biologically active drug molecule or a ligand for scavenging of metal ions [11,12]. Examples of these functionalized surface groups will be discussed under the various magnetic nanoparticle applications.

\section{PROPERTIES OF MAGNETIC NANOPARTICLES}

Ferromagnetic materials are subdivided into areas known as domains [13]. In an unmagnetized sample, the moments of these domains are randomly orientated, but tend to align themselves in the direction of an external applied magnetic field. As the particle size approaches a certain minimum critical size, often in the nanoscale range, the formation of domain walls becomes energetically unfavorable. Changes in magnetization occur through the rotation of spins rather than through the motion of domain walls. Particles exhibiting these properties are called single domain. As particle size is decreased further, spins are affected by thermal fluctuations and the particles become superparamagnetic [1,2].

This superparamagnetic property of materials is useful in that individual particles become magnetized only when exposed to an external magnetic field, but exhibit no remanent magnetization when the field is removed. In addition, the particle size provides a large surface area for functionalization which lends itself to applications of small dimensions of interest.

In this paper, three applications for which the magnetic nanoparticle properties are exploited will be discussed, namely, densimetric separation, medical applications, and effluent processing and metal ion removal.

\section{APPLICATIONS OF MAGNETIC NANOPARTICLES}

\section{Densimetric separation}

Magnetic liquids are stable colloidal dispersions or suspensions of single-domain nanosized particles, coated with a surfactant and suspended in a hydrophobic or hydrophilic carrier liquid [9]. These liquids exhibit superparamagnetic behavior. Separation of nonmagnetic materials into components of different densimetric composition is a sink-float technique which makes use of magnetic liquids.

Two fundamental forces act on a given volume $(V)$ of magnetic liquid when it is placed in a magnetic field gradient. These forces are the gravitational force $\left(\boldsymbol{F}_{\mathrm{g}}\right)$ and the magnetic traction force $\left(\boldsymbol{F}_{\mathrm{m}}\right)$. The total force on a volume of magnetic liquid is given as [15]:

$$
\begin{aligned}
\boldsymbol{F} & =\boldsymbol{F}_{\mathrm{g}}+\boldsymbol{F}_{\mathrm{m}} \\
& =\rho V \mathbf{g}+\mu_{0} M V \frac{\partial H}{\partial z} \frac{\boldsymbol{g}}{g} \\
& =\left(\rho+\mu_{0} \frac{M}{g} \frac{\partial H}{\partial z}\right) V \mathbf{g}
\end{aligned}
$$

Where $\rho$ is the density of the magnetic liquid, $\mu_{\mathrm{o}}$ is the magnetic permeability of a vacuum, $M$ is the magnetization of the fluid, $H$ is the magnetic field strength, $\partial H / \partial z$ is the vertical magnetic field gradient, and $\boldsymbol{g}$ is the gravitational acceleration.

The expression in parentheses in eq. 1 can be viewed as the apparent density of the fluid if it is assumed that the magnetic field gradient is parallel to gravity and of the same sense [15]. It is possible to control the apparent density of the magnetic fluid by changing the magnetic field gradient to which the fluid is exposed. 
A particle suspended in a body of magnetic liquid and under action of a magnetic field gradient is acted upon by a gravitational and magnetic traction force in the downward direction and a gravity-related buoyancy force $\left(\boldsymbol{F}_{\mathrm{gb}}\right)$ and magnetically induced buoyancy force $\left(\boldsymbol{F}_{\mathrm{mb}}\right)$ in the upward direction. If $\boldsymbol{F}_{\mathrm{g}}+\boldsymbol{F}_{\mathrm{m}}<\boldsymbol{F}_{\mathrm{gb}}+\boldsymbol{F}_{\mathrm{mb}}$, the particle will float (the particle density is lower than the magnetic fluid apparent density). Conversely, if $\boldsymbol{F}_{\mathrm{g}}+\boldsymbol{F}_{\mathrm{m}}>\boldsymbol{F}_{\mathrm{gb}}+\boldsymbol{F}_{\mathrm{mb}}$, the particle will sink (the particle density is greater than the magnetic fluid apparent density) [16].

For example, if a mixture of materials of densities $3.3,3.5$, and $3.7 \mathrm{~g} / \mathrm{cm}^{3}$ is to be separated into its respective fractions, it can be exposed to a magnetic liquid of apparent density $3.4 \mathrm{~g} / \mathrm{cm}^{3}$. Material of density $3.3 \mathrm{~g} / \mathrm{cm}^{3}$ will float. The dense material fraction can be subjected to magnetic liquid of apparent density $3.6 \mathrm{~g} / \mathrm{cm}^{3}$ from which the floats and sinks fractions ( 3.5 and $3.7 \mathrm{~g} / \mathrm{cm}^{3}$, respectively) can be recovered. Such a separation may be extended to a variety of nonmagnetic materials such as coal, diamond, or nonmagnetic scrap metal.

\section{Potential medical applications}

The use of magnetic nanoparticles in medical applications is a novel and highly interdisciplinary field offering great potential in therapeutic and diagnostic testing, in vitro and in vivo [17]. Initial medical applications used iron powder or magnetite directly in treatment methods. In this form, however, particles are recognized by the macrophages of the mononuclear phagocyte system and are eliminated from the body [12]. In order to improve biocompatibility, to reduce toxicity and to ensure non-immunogenicity, particles have been encapsulated (e.g., with chitosan, dextran, poly(lactic acid), starch, carbon, polysaccharides, gelatine, and proteins) to yield "stealth" particles $[12,18]$.

One of the main envisaged therapeutic applications of coated magnetic nanoparticles is for targeted chemotherapeutic drug delivery to tumors. Particles coated with a drug could be injected intravenously, transported to a site of action (e.g., cancerous tumor or arterial blockage) and be retained at the site by application of a magnetic field gradient. This form of drug delivery is advantageous in that a specific site in the body can be targeted by the magnetic field gradient, the doses required for systemic drug delivery are reduced, localized drug levels can be increased significantly with reduced potential toxic side effects at nontargeted tissues, and a prolonged release of high localized drug concentrations at a required site can be obtained [3,12]. An interesting extension of this technique is the use of implanted magnetized stents which can be used as capture sites for magnetic particles carrying therapeutic agents and offer the possibility of reapplication of a tailored drug and optimum dosage $[19,20]$.

A second important therapeutic application is in the field of hyperthermia, which involves heating organs or tissues to between 41 and $46^{\circ} \mathrm{C}$ to obtain tumor cell necrosis [21]. The application of an external alternating magnetic field to nanosized magnetic particles causes heating via hysteresis energy losses [17].

Superparamagnetic particles are used as magnetic resonance imaging (MRI) contrast agent in diagnostics applications. MRI may be used to enhance the image contrast between normal and diseased tissue and/or indicate the status of organ functions or blood flow [17]. Small superparamagnetic iron oxides (SPIOs) have been developed for imaging liver metastases and to distinguish loops of bowel from other abdominal structures [12].

Medical applications require particles with high saturation magnetization, exhibiting superparamagnetic behavior and small enough to interact in the region of interest, e.g., to promote tissular diffusion [12]. (Large particles may irritate surrounding tissue or embolize small blood vessels and capillaries [5].) Fundamental research must still be performed into areas such as the uniformity of magnetic particles with an equal probability of magnetic capture and determination of the fate of the particles in the body [12]. Despite much fundamental research still to be conducted, the potential for use of magnetic nanoparticles in a variety of biomedical applications such as for cell separation [22], "lab-on-achip" applications [23,24], and for the extraction, purification and re-injection of patient stem cells after cancer treatment [12] is significant. 


\section{Effluent processing and metal ion removal}

\section{Introduction}

Bare magnetic support materials have been used for effluent processing and metal ion removal through an electrostatic interaction in a magnetic flocculation-precipitation system. For example, for a magnetite particle surface, the charge on the oxide surface can be established by the dissociation or ionization of surface hydroxyl groups. Adsorption or desorption of protons depends on the $\mathrm{pH}$ of the solution represented by the following dissociation reactions $[11,25]$ :

$$
\begin{aligned}
& \text { Surface } \mathrm{FeOH}+\mathrm{H}^{+} \leftrightarrow \text { Surface } \mathrm{FeOH}_{2}^{+} \\
& \text {Surface } \mathrm{FeOH}+\mathrm{OH}^{-} \leftrightarrow \text { Surface } \mathrm{FeO}^{-}+\mathrm{H}_{2} \mathrm{O}
\end{aligned}
$$

We have become interested in potential applications of magnetic nanoparticles for heavy metal ion removal from process effluents. Although a variety of examples exist for the use of bare magnetic particles for species extraction in effluent processing and metal ion removal [26-29], to illustrate this application, work performed in our department focusing on base metal and platinum group metals (PGMs) research will be discussed.

Solvent or liquid-liquid extraction is used for the extraction and isolation of a wide range of components, e.g., metals or impurities from a variety of feed streams. The selected component is removed from an aqueous phase using an organic extractant and is then recovered from the organic phase usually by transferral of the component into a second aqueous phase [30,31].

The speed and ease of phase separation after extraction are important factors in solvent extraction and directly affect the retention time in a system [32]. In order to potentially improve the speed and ease of phase separation after solvent extraction, it was decided to compare a conventional solvent extraction system to a system in which the liquid organic extractant is incorporated into a magnetic liquid, thereby conferring magnetic properties to the extractant (as has been previously reported on one occasion [33]).

An aqueous cobalt sulfate/potassium thiocyanate solution was used as a model for the extraction studies. The pink color of this solution is as a result of the pink octahedral $\left[\mathrm{Co}(\mathrm{NCS})_{4}\left(\mathrm{H}_{2} \mathrm{O}\right)_{2}\right]^{2-}$ complex which is formed. Vogel reported the cobalt(II)-thiocyanate analytical test in which a bluish color is obtained upon the addition of acetone to an aqueous solution of cobalt thiocyanate. This color is accepted to be the anionic tetrahedral species, $\left[\mathrm{Co}(\mathrm{NCS})_{4}\right]^{2-}$, which forms as the activity of the water is reduced [34]. This property is convenient for studying this system by means of UV-vis absorbance spectra recorded before and after addition of the extractant (in magnetic liquid or other organic solvent) to an aqueous solution of $\mathrm{CoSO}_{4} \cdot 7 \mathrm{H}_{2} \mathrm{O} / \mathrm{KSCN}$. We used magnetic liquids in conjunction with a liquid anion exchanger, tricapryl methyl ammonium chloride (Aliquat 336), to extract the blue anionic $\left[\mathrm{Co}(\mathrm{NCS})_{4}\right]^{2-}$ from the aqueous phase.

While the incorporation of extractants into a magnetic liquid as an alternative to conventional hydrocarbon diluents may be promising, particularly in terms of speed of phase separation, magnetite is soluble at pHs lower than approximately 4 [25]. Magnetic liquid resistance to various acidic reagents often required for stripping and regeneration of the extractant may be limited. In order to improve the resistance at low $\mathrm{pH}$, encapsulation of the magnetic particles coated by silica was proposed by a method as discussed in the experimental section.

\section{Experimental}

$\left[\mathrm{Co}(\mathrm{SCN})_{4}\left(\mathrm{H}_{2} \mathrm{O}\right)_{2}\right]^{2-}$ was extracted from an aqueous solution $(15 \mathrm{ml}, 17 \mathrm{mmol} / \mathrm{l}$ cobalt sulfate/potassium thiocyanate solution, 20 times molar excess KSCN in Milli-Q water, $\mathrm{pH} 6$ ) using the combinations of extractant and carrier solvent $(5 \mathrm{ml})$ as indicated in Table 1 by agitation $(110 \mathrm{rpm})$ on a Labcon horizontal shaker $(10 \mathrm{~min})$. Triplicates were prepared for all extraction test samples. Absorbance was determined using a GBC UV-vis Cintra 10e Spectrometer. A wavelength scan from 400 to $700 \mathrm{~nm}$ at 
$200 \mathrm{~nm} / \mathrm{min}(0.4 \mathrm{~nm}$ step size and $1.5 \mathrm{~nm}$ slit width) was performed. The maximum absorbance at $512.3 \mathrm{~nm}$ was used to calculate the percentage extraction. The average and standard deviation of the triplicates was calculated, and the percentage extraction determined as a function of the original $\mathrm{CoSO}_{4} \cdot 7 \mathrm{H}_{2} \mathrm{O} / \mathrm{KSCN}$ concentration. Settling rates were determined according to industrial experimental standards by measuring the height of the phase interface as a function of time [31].

Table 1 System of extractants and carrier solvents used for extraction studies.

\begin{tabular}{|c|c|c|}
\hline Extractant & Carrier solvent & $\begin{array}{l}\text { To determine extraction of } \\
{\left[\mathrm{Co}(\mathrm{SCN})_{4}\left(\mathrm{H}_{2} \mathrm{O}\right)_{2}\right]^{2-} \text { by: }}\end{array}$ \\
\hline Magnetite $^{\mathrm{a}}$ & $\begin{array}{l}\text { None (magnetite added directly to } \\
\text { cobalt thiocyanate aqueous solution) }\end{array}$ & Bare magnetite \\
\hline None & $\begin{array}{l}\text { Magnetic liquid }{ }^{\mathrm{b}} \text { (consisting of } \\
\text { nanosized magnetite coated } \\
\text { with oleic acid and suspended } \\
\text { in kerosene) }\end{array}$ & $\begin{array}{l}\text { Magnetic liquid (containing } \\
\text { magnetite but no extractant) }\end{array}$ \\
\hline $\begin{array}{l}\text { Tricapryl methyl ammonium chloride } \\
\text { (ion-pair extractant with commercial } \\
\text { name Aliquat } 336)^{\mathrm{c}}\end{array}$ & Magnetic liquid & $\begin{array}{l}\text { Aliquat } 336 \text { in magnetic liquid } \\
\text { (modified extractant system) }\end{array}$ \\
\hline Tricapryl methyl ammonium chloride & $\begin{array}{l}\text { Shellsol } 2325 \text { (mixture of paraffinic, } \\
\text { naphthenic, and aromatic } \\
\text { hydrocarbons) }\end{array}$ & $\begin{array}{l}\text { Aliquat } 336 \text { in Shellsol } 2325 \\
\text { (conventional solvent } \\
\text { extraction system) }\end{array}$ \\
\hline $\begin{array}{l}\text { Methyl isobutyl ketone (MIBK, a } \\
\text { solvating extractant) }^{\mathrm{d}}\end{array}$ & Magnetic liquid & $\begin{array}{l}\text { MIBK in magnetic liquid } \\
\text { (modified extractant system) }\end{array}$ \\
\hline MIBK & Shellsol 2325 & $\begin{array}{l}\text { MIBK in Shellsol } 2325 \\
\text { (conventional solvent } \\
\text { extraction system) }\end{array}$ \\
\hline
\end{tabular}

asynthesized by the method of Massart [35].

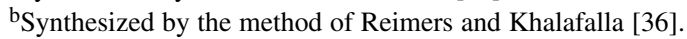

'Purchased from Aldrich.

dPurchased from Merck.

Magnetic particles were encapsulated in silica via the Stöber sol-gel method using a tetraethylorthosilicate precursor [37]. The particle surfaces were functionalized with $N$-[3-(trimethoxysilyl)propyl] diethylenetriamine and used for preliminary studies into the extraction of $\mathrm{Cu}^{2+}$ from a pH 4 and 6 acetate buffer solution with a ligand-to-metal molar ratio of 1:2. Metal concentrations were determined using a Varian ICP-AES with linear calibration. Characterization of coated particles was performed by transmission electron microscopy (TEM), elemental analysis, scanning electron microscopy/energy-dispersive spectrometry (SEM/EDS), Fourier transform infrared spectrometry (FTIR), and $\mathrm{X}$-ray diffraction (XRD) (data not reported here).

\section{Results and discussion}

Both the bare magnetite and magnetic liquid are capable of extracting the cobalt thiocyanate complex. The point of zero charge (PZC) for magnetite has been reported in the range of 6 to 8.2 [38-41]. At $\mathrm{pH}=6\left(\mathrm{CoSO}_{4} \cdot 7 \mathrm{H}_{2} \mathrm{O} / \mathrm{KSCN}\right.$ solution $\left.\mathrm{pH}\right)$, cobalt thiocyanate anions may be adsorbed onto the magnetite surface via $\mathrm{FeOH}_{2}{ }^{+}$groups [25]. With the addition of a surfactant (oleic acid) to the magnetite surface, as is the case in a magnetic liquid, it is possible that the PZC is lowered to approximately 4.5 [42]. If this is the case, the $\mathrm{FeO}^{-}$groups may dominate. However, even with a dominance of $\mathrm{FeO}^{-}$ groups, there may still be $\mathrm{FeOH}_{2}{ }^{+}$groups available for adsorption of the cobalt thiocyanate anions [25]. This was indeed observed as the cobalt thiocyanate anions were extracted by the magnetic liquid. Extraction kinetics by both the magnetite and magnetic liquid (no extractant) were rapid (80\% extraction in $24 \mathrm{~h}$ ) with the initial rapid attachment of species to the surface limited mainly by the diffusion 
of anions to the surface. An increase of approximately $10 \%$ extraction was observed over a further 44 days. This is attributed to diffusion into particle aggregates or crystal nanopores and structural rearrangement of the surface complexes [25].

The incorporation of Aliquat 336 into the magnetic liquid showed approximately $10 \%$ higher extraction than the conventional system as a result of the adsorption of the cobalt thiocyanate anions onto the surface of the magnetite.

In the magnetic liquid/MIBK system, the MIBK was removed from the aqueous solution after extraction by incorporation into a magnetic liquid (such that the concentration of MIBK in magnetic liquid was $8 \%(\mathrm{v} / \mathrm{v}))$. The magnetic liquid acted as both an extractant and as a scavenger for the MIBK.

In both cases (Aliquat 336 and MIBK systems), the percentage extraction by the modified system was the same or higher than for the conventional system. Phase separation was found to be $48-84 \%$ faster for the magnetic liquid system (depending on the extractant used).

The Stöber sol-gel method [37] yielded silica-coated magnetite particles in the region of 50-70 nm, many of which contained more than one magnetite core (see Fig. 1).

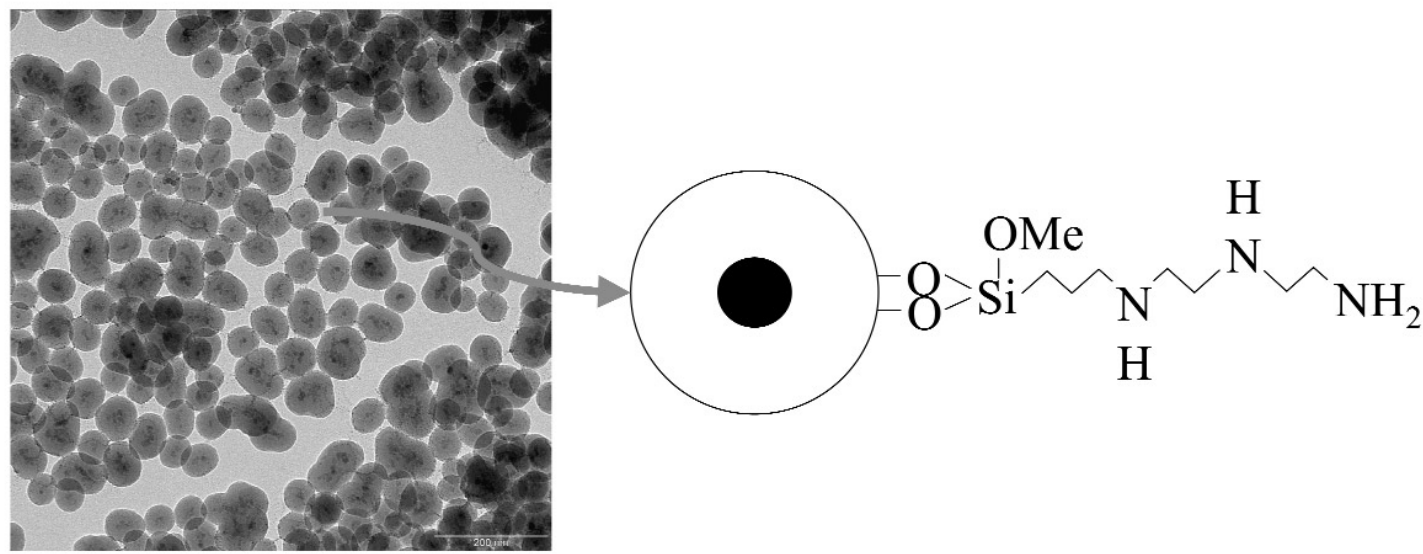

Fig. 1 TEM image of silica-coated magnetite particles showing schematic of diethylenetriamine-functionalized surface.

Figure 2 shows the percentage $\mathrm{Cu}^{2+}$ extraction for magnetite $\left(\mathrm{Fe}_{3} \mathrm{O}_{4}\right)$, silica-coated magnetite ( $\mathrm{FeSi}$ ), and diethylenetriamine functionalized magnetite (FeSiDETA). As the $\mathrm{pH}$ increases from 4 to 6 , more $\mathrm{FeO}^{-}$groups are available on the bare magnetite surface for $\mathrm{Cu}^{2+}$ extraction. The silica-coated magnetite particles show a lower percentage $\mathrm{Cu}^{2+}$ extraction at both $\mathrm{pH} 4$ and 6 as a result of their silica surface covering. Unfortunately, the silica coating does not provide complete shielding of the iron oxide from the $\mathrm{Cu}^{2+}$ solution and the higher percentage extraction occurring at $\mathrm{pH} 6$ as compared to $\mathrm{pH}$ 4 for the FeSi particles is probably as a result of ion pairing with exposed $\mathrm{FeO}^{-}$groups.

The functionalized particles (FeSiDETA) show the highest overall extraction compared to bare magnetite and FeSi particles. Extraction is believed to occur through a chelating ion exchange mechanism where coordination to $\mathrm{Cu}^{2+}$ readily takes place via the lone pairs of the amine groups [43].

The percentage dissolved iron for this system is low $(<2 \%)$. Studies will now be extended to the extraction of PGMs from more acidic solutions where the PGMs are well known to form very stable complex anions [44].

\section{Conclusions}

In solvent extraction, incorporation of extractants into magnetic liquids offers an advantageous alternative to conventional extractant solvents in that ease and speed of phase separation can be improved by 


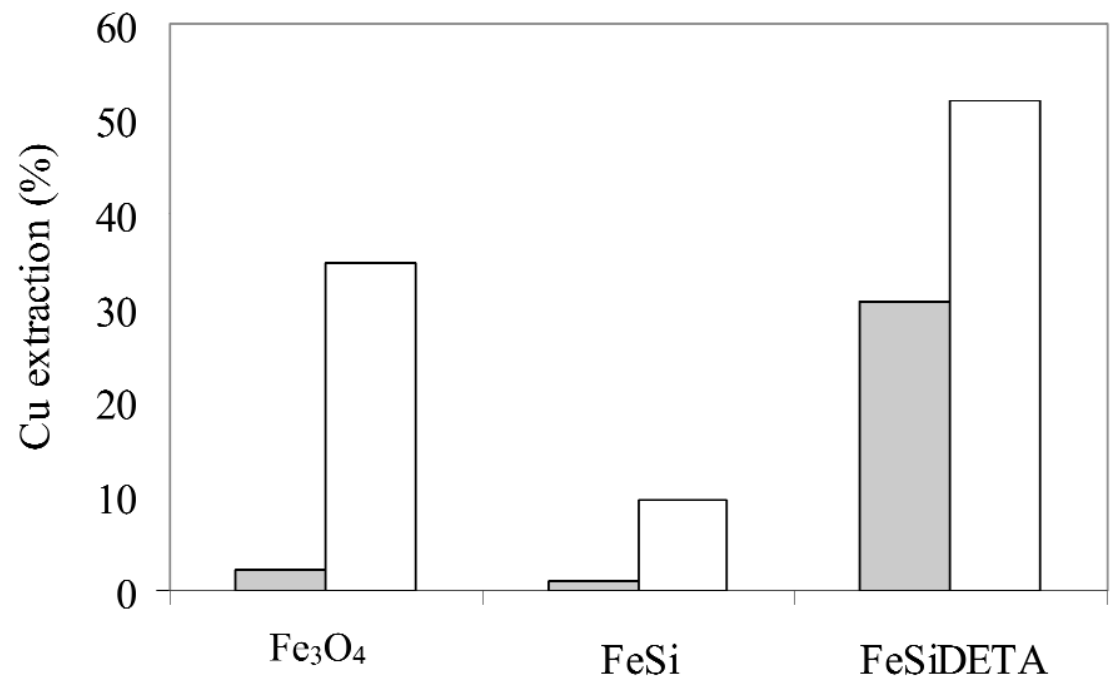

Fig. 2 Percentage $\mathrm{Cu}^{2+}$ extraction by $\mathrm{Fe}_{3} \mathrm{O}_{4}, \mathrm{FeSi}$, and FeSiDETA at $\mathrm{pH} 4$ (in gray) and $\mathrm{pH} 6$ (no color). A ligandto-metal ion molar ratio of 1 to 2 has been applied.

up to $84 \%$ without adversely affecting the percentage $\left[\mathrm{Co}(\mathrm{SCN})_{4}\left(\mathrm{H}_{2} \mathrm{O}\right)_{2}\right]^{2-}$ extraction. Coating of magnetite particles with a protective silica shell allows for $\mathrm{Cu}^{2+}$ extraction under more acidic conditions which would otherwise be unsuitable for bare magnetite particles.

\section{SUMMARY}

Magnetic nanoparticles, by virtue of their size and magnetic characteristics, lend themselves to a variety of applications. The magnetic core of a magnetic carrier may be used for the directing of the particle via a magnetic field. The large surface area provided by the magnetic nanoparticles for attachment of extractable species and functionalization with selected ligands allows for targeting of a selected species or for delivery of a species to a selected location. Their ability to be easily manipulated using a magnetic field makes these carriers a desirable option for use in, amongst others, biomedical and process engineering applications. Although certain limitations exist in terms of the range of magnetic influence and chemical resistance of carriers, much scope remains for the development of a large variety of new applications using magnetic carriers.

\section{ACKNOWLEDGMENTS}

The University of Stellenbosch, the National Research Foundation (NRF), Anglo Platinum, and THRIP are gratefully acknowledged for their financial assistance.

\section{REFERENCES}

1. M. A. Willard, L. K. Kurihara, E. E. Carpenter, S. Calvin, V. G. Harris. In Encyclopedia of Nanoscience and Nanotechnology, Vol. 1, H. S. Nalwa (Ed.), p. 815, American Scientific Publishers, Stevenson Ranch, CA (2004).

2. D. L. Leslie-Pelecky, R. D. Rieke. Chem. Mater. 8, 1770 (1996).

3. C. H. Ahn, J. W. Choi, H. J. Cho. In Encyclopedia of Nanoscience and Nanotechnology, Vol. 6, H. S. Nalwa (Ed.), p. 815, American Scientific Publishers, Stevenson Ranch, CA (2004). 
4. R. Müller, H. Steinmetz, R. Hiergeist, W. Gawalek. J. Magn. Magn. Mater. 272-276, 1539 (2004).

5. U. O. Häfeli, G. J. Pauer. J. Magn. Magn. Mater. 194, 76 (1999).

6. M. L. Vadala, M. A. Zalich, D. B. Fulks, T. G. St. Pierre, J. P. Dailey, J. S. Riffle. J. Magn. Magn. Mater. 293, 162 (2005).

7. H. Bönnemann, K. S. Nagabhushana. In Encyclopedia of Nanoscience and Nanotechnology, Vol. 1, H. S. Nalwa (Ed.), p. 177, American Scientific Publishers, Stevenson Ranch, CA (2004).

8. K. Inouye, R. Endo, Y. Otsuka, K. Miyashiro, K. Kaneko, T. Ishikawa. J. Phys. Chem. 86, 1465 (1982).

9. R. E. Rosensweig. Ferrohydrodynamics, Cambridge University Press, Cambridge (1985).

10. S. W. Charles, J. Popplewell. Ferromagnetic Materials: A Handbook on the Properties of Magnetically Ordered Substances, North-Holland Publishing, Amsterdam (1980).

11. J. Broomberg, S. Gélinas, J. A. Finch, Z. Xu. Magn. Elec. Sep. 9, 169 (1999).

12. U. O. Häfeli. Int. J. Pharm. 277, 19 (2004).

13. J. P. Jakubovics. Magnetism and Magnetic Materials, Cambridge University Press, Cambridge (1994).

14. N. Buske, H. Sonntag, T. Götze. Colloids Surf. 12, 195 (1984).

15. J. Svoboda. Magnetic Techniques for the Treatment of Materials, Kluwer Academic, Dordrecht (2004).

16. S. Nogita, I. Takashi. Hitachi Rev. 26, 139 (1977).

17. P. Tartaj. In Encyclopedia of Nanoscience and Nanotechnology, Vol. 1, H. S. Nalwa (Ed.), p. 177, American Scientific Publishers, Stevenson Ranch, CA (2004).

18. D. Portet, B. Denizot, E. Rump, J.-J. Lejeune, P. Jallet. J. Colloid Interface Sci. 238, 37 (2001).

19. A. J. Rosengart, M. D. Kaminksi, H. Chen, P. L. Caviness, A. D. Ebner, J. A. Ritter. J. Magn. Magn. Mater. 293, 633 (2005).

20. B. B. Yellen, Z. G. Forbes, D. S. Halverson, G. Fridman, K. A. Barbee, M. Chorny, R. Levy, G. Friedman. J. Magn. Magn. Mater. 293, 647 (2005).

21. A. Jordan, R. Scholtz, P. Wust, H. Fähling, R. Felix. J. Magn. Magn. Mater. 201, 413 (1999).

22. S. Sonti, A. Bose. J. Colloid Interface Sci. 170, 575 (1995).

23. M. Megens, M. Prins. J. Magn. Magn. Mater. 293, 702 (2005).

24. M. Tondra, A. Popple, A. Jander, R. L. Miller, N. Pekas, M. D. Porter. J. Magn. Magn. Mater. 293, 725 (2005).

25. R. M. Cornell, U. Schwertmann. The Iron Oxides, VCH, New York (1996).

26. W. Y. Chen, P. R. Anderson, T. M. Holsen. Res. J. WPCF 63, 958 (1991).

27. N. J. Anderson, B. A. Bolto, R. J. Eldridge, L. O. Kolarik, E. A. Swinton. Water Res. 20, 537 (1982).

28. B. A. Bolto, D. R. Dixon, E. A. Swinton, D. E. Weiss. J. Chem. Technol. Biotechnol. 29, 325 (1979).

29. S. Gélinas, J. A. Finch, A. J. Vreugdenhill. Int. J. Miner. Process. 59, 1 (2000).

30. M. Cox. Ullmann's Encyclopedia of Industrial Chemistry, B3, 6-43-6-57 (1988).

31. Cognis Corporation Ion-Transfer Technology. Cognis MCT Redbook, <www.cognis.com> (2005).

32. R. Kunin, A. G. Winger. Angew. Chem., Int. Ed. Engl. 1, 149 (1962).

33. J. Y. Hwang. U.S. Patent No. 5,043,070 (1991).

34. H. W. Vogel. Ber. 12, 2313 (1979).

35. R. Massart. IEEE Trans. Magn. 17, 1247 (1981).

36. G. W. Reimers, S. E. Khalafalla. U.S. Patent No. 3,843,540 (1973).

37. G. A. van Ewijk, G. J. Vroege, A. P. Philipse. J. Magn. Magn. Mater. 210, 31 (1999).

38. S. K. Milonjic, M. M. Kopenci, Z. E. Ilic. J. Radioanal. Chem. 78, 15 (1983).

39. M. Kosmulski. J. Colloid Interface Sci. 275, 214 (2004). 
40. Z.-X. Sun, F.-W. Su, W. Forsling, P.-O. Samskog. J. Colloid Interface Sci. 197, 151 (1998).

41. D. J. Wesolowski, M. Machesky, D. A. Palmer, L. M. Anovitz. Chem. Geol. 167, 193 (2000).

42. P. Parsonage. Trans. Inst. Min. Metall. 93, C37 (1984).

43. P. N. Nesterenko, A. V. Ivanov, N. A. Galeva, G. B. C. Seneveratne. J. Anal. Chem. 52, 736 (1997).

44. A. Warshawsky, M. N. B. Fieberg, P. Mihalik, T. G. Murphy, Y. B. Ras. Sep. Purif. Methods 9, 209 (1980). 